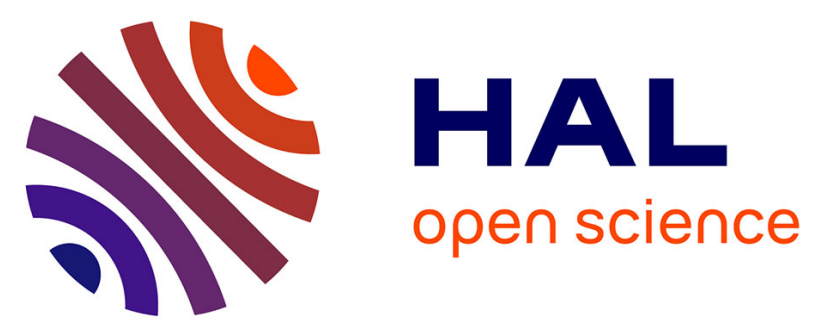

\title{
Forkhead box transcription factors Foxa1 and Foxa2 are important regulators of Muc2 mucin expression in intestinal epithelial cells
}

Maria van Der Sluis, Audrey Vincent, Janneke Bouma, Anita Korteland-van Male, Johannes B van Goudoever, Ingrid B Renes, Isabelle van Seuningen

\section{To cite this version:}

Maria van Der Sluis, Audrey Vincent, Janneke Bouma, Anita Korteland-van Male, Johannes B van Goudoever, et al.. Forkhead box transcription factors Foxa1 and Foxa2 are important regulators of Muc2 mucin expression in intestinal epithelial cells. Biochemical and Biophysical Research Communications, 2008, 10.1016/j.bbrc.2008.02.158 . hal-02905687

\section{HAL Id: hal-02905687 \\ https://hal.science/hal-02905687}

Submitted on 29 Sep 2020

HAL is a multi-disciplinary open access archive for the deposit and dissemination of scientific research documents, whether they are published or not. The documents may come from teaching and research institutions in France or abroad, or from public or private research centers.
L'archive ouverte pluridisciplinaire HAL, est destinée au dépôt et à la diffusion de documents scientifiques de niveau recherche, publiés ou non, émanant des établissements d'enseignement et de recherche français ou étrangers, des laboratoires publics ou privés. 


\title{
Forkhead box transcription factors Foxa1 and Foxa2 are important regulators of Muc2 mucin expression in intestinal epithelial cells
}

\author{
Maria van der Sluis ${ }^{\mathrm{a}, 1}$, Audrey Vincent ${ }^{\mathrm{c}, 1}$, Janneke Bouma ${ }^{\mathrm{a}}$, Anita Korteland-Van Male ${ }^{\mathrm{a}, \mathrm{b}}$, \\ Johannes B. van Goudoever ${ }^{a}$, Ingrid B. Renes ${ }^{a}$, Isabelle Van Seuningen ${ }^{c, *}$ \\ a Department of Paediatrics, Division of Neonatology, Erasmus MC-Sophia Children's Hospital, Rotterdam, The Netherlands \\ b Department of Paediatrics, Division of Gastroenterology, Erasmus MC-Sophia Children's Hospital, Rotterdam, The Netherlands \\ ${ }^{\mathrm{c}}$ Department of Paediatrics, Inserm, U837, Centre de Recherche Jean-Pierre Aubert, Place de Verdum, 59045 Lille, France
}

\section{A R T I C L E I N F O}

\section{Article history:}

Received 27 February 2008

Available online $\mathrm{xxxx}$

\section{Keywords:}

Mucin

Muc2

Foxa

Goblet cell

Differentiation

Transcription

Epithelial

Regulation

Expression

\begin{abstract}
A B S T R A C T
The mucin Muc2 is the main component of the intestinal mucus layer and thus plays important roles in intestinal protection. Therefore, it is important to understand its regulation during goblet cell differentiation. Foxa1 and Foxa2 forkhead box transcription factors (TFs) participate in transcriptional programs governing intestinal cell differentiation. Using immunohistochemistry, we showed a spatio-temporal pattern of expression of both TFs in developing and adult mouse intestine and their expression in Muc2-expressing intestinal cells. Down-regulation of Foxa1 and Foxa2 by RNA interference in cultured intestinal cells decreased Muc2 mRNA level by half, and abolished Muc2 protein expression. Chromatin immunoprecipitation and gel shift assays showed that these two TFs directly bind to the Muc2 promoter. Co-transfection experiments indicated that both TFs activate the Muc2 promoter and that mutations of three Foxa cis-elements inhibit Muc2 transactivation. In conclusion, this work identifies Foxa1 and Foxa2 as important regulators of Muc2-expression in the intestine.
\end{abstract}

(c) 2008 Elsevier Inc. All rights reserved.
The mucin Muc2 is the main protein component of intestinal mucus, which provides a physical barrier between epithelium and luminal content $[1,2]$. The protective role of Muc2 is definitively proven by the development of spontaneous colitis and intestinal tumours in Muc2 knockout mice [3]. Since regulatory systems, which are active during development, are often reactivated in cancer, it is hypothesized that they could be responsible for aberrant MUC2-expression in intestinal cancers and other intestinal disorders [2].

In humans, MUC2 mRNA is expressed during embryonic development of the intestine, in a specific spatio-temporal pattern of expression [4]. Moreover, Muc2-expression is associated with differentiation of goblet cells and has been identified as a marker of these cells [3]. Altogether, this suggests that Muc2 gene transcription is under the influence of transcription factors (TFs) that regulate the differentiation of endoderm-derived cell types during intestinal development and more particularly goblet cell differentiation.

\footnotetext{
* Corresponding author. Fax: +33 320538562 .

E-mail address: isabelvs@lille.inserm.fr (I. Van Seuningen).

Both authors contributed equally to this work.
}

Such TFs include families of the caudal-related homeobox (CDX), GATA, and hepatocyte nuclear factors (HNF-3), also known as forkhead box A (FOXA), TFs [2,5-7]. Their participation in maintaining a functional epithelium is the result of a tight spatio-temporal regulation of cell- and/or tissue-specific genes, among which we recently identified both human MUC2 and murine Muc2 as targets of CDX1, CDX2 and Gata-4, respectively [8,9]. However, no information regarding Muc2 regulation by Foxa TFs is available. Foxa 1 and Foxa2 play important roles in definitive endoderm formation during gastrulation and differentiation of gut endoderm tissues [7,10]. Foxa1 and Foxa 2 mRNAs have been found expressed in embryonic endoderm and adult intestine [6,7,10-12]. These TFs belong to the winged helix/forkhead class of DNA binding proteins, possessing highly conserved DNA binding domains [12]. As transcription activators, Foxa TFs bind the DNA consensus sequence $5^{\prime}$-GATTATTGACTT- $3^{\prime}$ as monomers $[13,14]$. In a previous study, in which we identified Gata-4 as an important regulator of the murine Muc2 gene, we also found a Foxa1/Foxa2 cis-element in the close vicinity of the Gata-4 site [9]. Knowing that these two families of TFs may synergize to regulate intestine-specific target genes [15-18], we further analyzed the Muc2 promoter sequence, and found three more putative Foxa binding sites within the promoter. 
Altogether these data suggested that Foxa TFs may be part of the complex transcriptional machinery driving the spatio-temporal expression of Muc2 in the intestine. In order to test this hypothesis, we undertook to (i) investigate Foxa1, Foxa2, and Muc2-expression during differentiation of goblet cells in the developing and adult mouse intestine, (ii) study Muc2 regulation by Foxa1 and Foxa2, and (iii) evaluate a possible synergy with Gata-4.

\section{Materials and methods}

Animals. Pregnant Balb/c mice (Charles River, Maastricht, The Netherlands) were housed as in [16]. Pregnant females were sacrificed by cervical dislocation, embryos were isolated and the intestine was excised at embryonic (E)15.5, E17.5, E18.5, and postnatal (P)1.5 days and adults. The small intestine was fixed in $4 \%$ paraformaldehyde in PBS and prepared for light microscopy. All experiments were performed with the approval of the Animal Studies Ethics Committee of the Erasmus Medical Centre (Rotterdam, The Netherlands).

Immunohistochemistry. Five micrometers thick paraffin sections were cut and processed for immunohistochemical stainings [9]. Anti-Muc2 (sc-15334), antiFoxa1 (sc-6553X), and anti-Foxa2 (sc-9187X) antibodies (1:1000; Santa Cruz Biotechnology, Tebu-Bio, Le Perray en Yvelines, France) were incubated overnight at $4{ }^{\circ} \mathrm{C}$. To visualize goblet cells, sections were stained with Alcian Blue 8GX (BDH, Brunschwig Chemie, Amsterdam, The Netherlands).

Cell culture, total cellular and nuclear extract preparations. The Muc2-expressing murine rectal cancer cell line CMT-93 was cultured as in [9], nuclear extracts were prepared as in [19] and total cellular extracts as in [20]. Protein content $(2 \mu \mathrm{l})$ was measured using the bicinchoninic acid method (Pierce, Bezons, France). Muc2 $(1: 100)$ Western-blotting was carried out as in [20].

Small interfering RNA (siRNA) assays. CMT-93 cells were seeded $24 \mathrm{~h}$ before transfection in 24-well tissue culture plates at a density of $23 \times 10^{3}$ cells/well in antibiotic free medium. Cells were transfected as in [20] with $100 \mathrm{nM}$ of either mouse Gata-4, Foxa1, or Foxa2 SMARTpool ${ }^{\circledR}$ siRNAs, or combinations using $1 \mu \mathrm{l}$ of DharmaFECT $^{\text {TM }}$ two transfection reagent (Dharmacon, Brebières, France). Controls included mock transfected cells, cells transfected with either siCONTROL ${ }^{\text {al }}$ Gapdh or Non-Targeting siRNAs. Each siRNA was assayed in triplicate in at least three experiments. Total RNA was isolated using the Nucleospin RNA II kit (Macherey-Nagel, Hoerdt, France) and used $(1 \mu \mathrm{g})$ to prepare cDNA using oligod(T) $(1 \mu \mathrm{l})$ and recombinant reverse transcriptase M-MLV $(1 \mu \mathrm{l}$ ) (Promega, Charbonnières, France). PCR was performed on cDNA $(5 \mu \mathrm{l})$ using specific primers (MWG-Biotech, Ebersberg, Germany) for mouse Muc2 mucin gene and mouse Gapdh [8]. Densitometric analysis of DNA bands was carried out using the GelAnalyst-GelSmart software (Clara Vision, Orsay, France).

Cell transfection and luciferase assays. Cell transfections and co-transfections were performed as in [9]. All plasmids used for transfection were prepared using the Endofree plasmid Maxi kit (Qiagen, Courtaboeuf, France).

Site-directed mutagenesis. QuickChange site-directed mutagenesis kit (Stratagene, Amsterdam, The Netherlands) was used to generate site specific mutations in the four Foxa binding sites present in the $-221 /+29$ Muc2 promoter construct. All mutations were confirmed by DNA sequencing using RV3 and GL2 primers (Promega).

Chromatin Immunoprecipitation Assay (ChIP). ChIP assays with CMT-93 cells $\left(1.0 \times 10^{8}\right)$ and PCR conditions were as in [20]. An aliquot of the total supernatant was removed as a control (input) and the rest was divided into fractions to be precipitated with either $4 \mu \mathrm{g}$ of specific antibodies (anti-Foxa1, anti-Foxa2, anti-Gata-4 (sc-1237X), SantaCruz Biotechnology) or with normal rabbit IgGs (Upstate, Euromedex, Mundolsheim, France). Samples ( $50 \mathrm{ng}$ ) were then subjected to PCR analysis with primers covering the $-269 /-31$ region of $M u c 2$ promoter (forward primer: 5'-AAAGGAATGGAGTTAGTTCAC-3' and reverse primer: 5'-CTTAGCAGGCATCCG AGG-3'). Fifteen microliters of the PCR products (239 bp) were analyzed on a $2 \%$ agarose gel.

\section{Results and discussion}

Foxa1 and Foxa2 are expressed in Muc2-expressing goblet cells of the mouse small intestine

Immunohistochemical studies performed on developing and adult mouse small intestine, showed that Muc2 was not detectable at E15.5 (Fig. 1A). As from E17.5, goblet cells expressed the mucin Muc2 (Fig. 1C, E, and $\mathrm{H}$ ).

At E15.5, Foxa1 protein was uniformly expressed by all cells in the developing gut (not shown), whereas Foxa2 expression was restricted to the pseudostratified epithelium (Fig. 1B). Foxa1 was expressed by all epithelial and goblet cells in developing crypts and villi, with a slight decrease in staining intensity towards the tip of the villi (Fig. 1F and I showing E18.5 and adult, respectively). This is in agreement with previous work showing the same pattern of Foxa1 expression along the crypt-villus axis [21]. Based on the expression pattern of Foxa1 within the intestine, and its function as regulator of p27, cyclinD1, and E-cadherin expression [22,23], Foxa1 may be involved in the regulation of the balance between intestinal epithelial proliferation and differentiation. Moreover, binding of Foxa1 facilitates opening of the chromatin, and therefore enhances binding of cofactors and/or repressors [23].

From E17.5 until adulthood the expression of Foxa2 showed a spatio-temporal pattern. More specifically, Foxa2 was observed in the nuclei of the intervillus region (from E17.5 till P1.5, Fig. 1D, G, and Supplemental data), in the crypts (adult mice, Fig. 1J) and in goblet cells (Alcian blue staining of glycoproteins in secretory granules) along the villi (Fig. 1D, G, and J). Foxa2 expression in the region where intestinal stem cells and proliferating cells reside, namely in the intervillus/crypt region, suggests involvement of Foxa2 in maintaining epithelial cells in an undifferentiated state probably to stimulate epithelial proliferation. This hypothesis is supported by results showing that isoforms of the winged helix transcription factors, more specifically, forkhead box homolog $11 \mathrm{~A}$ and $-11 \mathrm{~B}$, induced proliferative signals [13] Localization of Foxa2 in the crypts of the small intestine also corresponds to results previously described [21]. Our results indicate that Foxa 1 and Foxa 2 are expressed in intestinal cells along the villi with distinct patterns. Very interestingly, whereas Foxa1 was found expressed in nuclei of all cell types, Foxa2 expression was detected almost exclusively in differentiated goblet cells. This strongly suggests that Foxa2 is also an important actor of goblet cell differentiation.

\section{Foxa1 and Foxa2 regulate endogenous Muc2-expression}

Since we found that Foxa1 and Foxa2 were expressed in intestinal goblet cells, a cell type for which the mucin Muc2 is a phenotypic marker, we undertook to study Muc2 regulation by these two TFs. Muc2 transcriptional regulation by Foxa 1 and Foxa 2 was studied in the murine rectal cancer cell line CMT-93, which expresses Muc2 mRNA (Supplemental data) as well as Foxa1 and Foxa2 proteins (Supplemental data). Down-regulation of Foxa1 and Foxa2, by siRNA, respectively, resulted in a $60 \%$ and $40 \%$ decrease of the amount of Muc2 mRNA (Fig. 2A) and abolished Muc2 protein expression (Fig. 2B). Altogether, this shows that Foxa1 and Foxa2 regulate endogenous Muc2-expression.

To identify Foxa responsive regions within Muc2 promoter, cotransfection experiments were carried out in the presence of the Muc2-pGL3 promoter construct $-221 /+29$ (containing three putative Foxa binding sites and the Foxa1/Foxa2 cis-element previously identified [9], Fig. 2C) and Foxa1 (black bars) or Foxa2 (gray bars) expression vectors. The luciferase diagram indicates that overexpression of Foxa1 and Foxa2 resulted in a 6- and 4-fold increase of $M u c 2$ promoter activity, respectively, demonstrating that both Foxa1 and Foxa2 induce Muc2 transcription.

Foxa1 and Foxa2 interact with chromatin encompassing the Muc2 promoter by binding to two cis-elements

ChIP assays using specific PCR primers covering the $-269 /-31$ region of the $M u c 2$ promoter indicate that Foxa1 and Foxa2 bind to the Muc2 promoter in vivo (Fig. 2D). By EMSA we then showed that the two TFs bind to the two cis-elements at $-180 /-175$ (T262, Foxa dist.) and $-150 /-144$ (T275, Foxa ext.) (Supplemental data). 

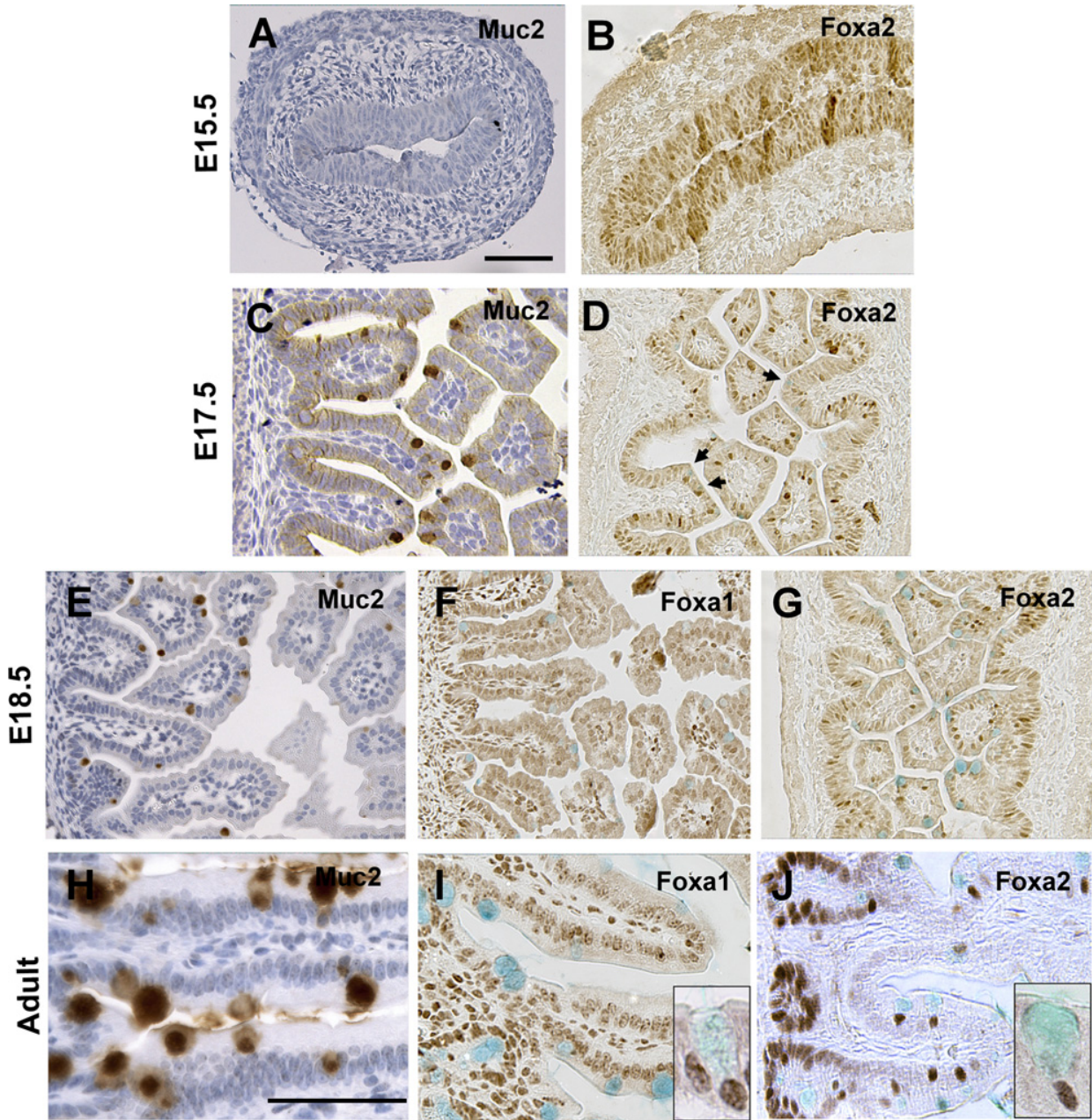

Fig. 1. Spatio-temporal expression of Muc2, Foxa1 and Foxa2 in the developing and adult mouse small intestine. Muc2 (A and C) and Foxa2 (B and D) at E15.5 and E17.5, respectively. Muc2, Foxa1, and Foxa2 stainings of E18.5 (E-G), and adult (H-J) small intestine. Inserts show a close-up of a goblet cell stained with Foxa1 (I) and Foxa2 (J). Magnifications in A-G and $\mathrm{H}-\mathrm{J}$ are equal, respectively, bar representing $75 \mu \mathrm{m}$.

\section{A}

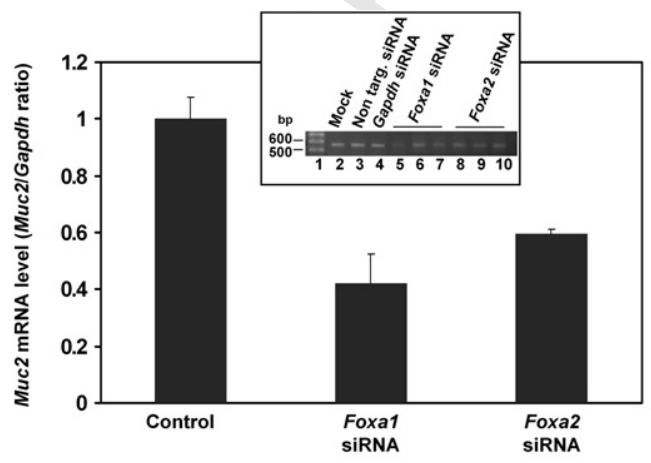

C

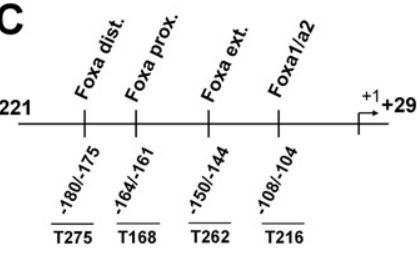

B

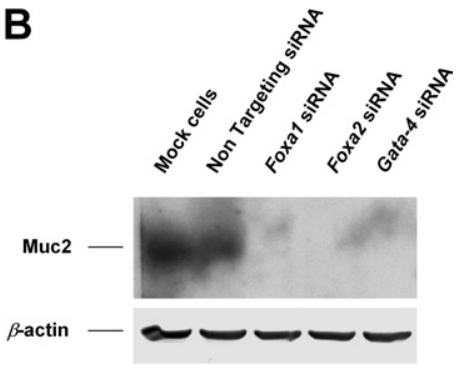

D

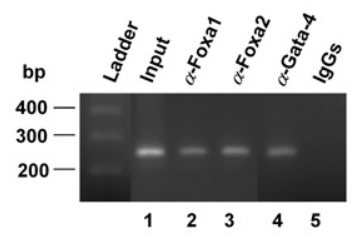

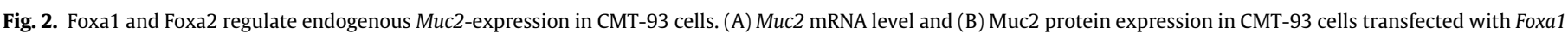

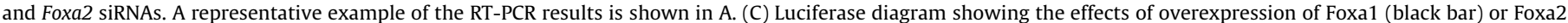

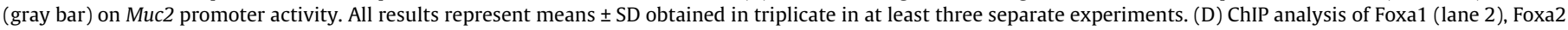
(lane 3), Gata-4 (lane 4), and rabbit IgGs (lane 5) binding to the Muc2 promoter. Input (lane 1). 
Gata-4 and Foxa transcription factors do not synergize to activate the Muc2 promoter

In order to establish which Foxa binding site(s), among those identified, were playing a critical role in regulating Muc2 transcription, we made single Foxa mutants (Fig. 3A). Mutations of single Foxa sites within the promoter indicated that mutations at sites $-164 /-161,-150 /-144$, and $-108 /-104$ led to complete inhibition of transactivation of the $M u c 2$ promoter by both Foxa 1 and Foxa2 (Fig. 3A). Mutation of the most distal Foxa site at $-180 /$ -175 led to $60 \%$ (Foxa 1 ) and 55\% (Foxa2) inhibition of Muc2 promoter activity, respectively. This indicates that each of the Foxa sites is essential for efficient transactivation of the Muc2 promoter both by Foxa 1 and Foxa2.

Having previously shown that Gata-4 was an important regulator of Muc2 [9], that down-regulation of Gata-4 by siRNA inhibited Muc2 protein expression (this report, Fig. 2B) and that Foxa and
Gata-4 TFs bind to cis-elements close to each other within the Muc2 promoter, we hypothesized that they could synergize. In order to show this, we made double Gata-4/Foxa mutants. First, single mutations of Gata sites within the promoter indicated that mutations at sites $-168 /-165$ and $-158 /-155$ (T168) did not lead to full inhibition of $M u c 2$ promoter transactivation by Gata-4 (55\% remaining, Fig. 3B, black bar). This suggested that the most proximal Gata-4 site (-99/-96) was also active. Indeed, when mutating this site, the transactivating effect of Gata-4 on the $-221 /+29$ promoter construct was completely lost.

Since mutation of the T168 Gata- 4 binding site did not lead to full inhibition of Muc2 promoter activity, double mutants of the T168 Gata site with each of the Foxa elements, were made to assess whether double mutations could lead to total inhibition of the promoter activity (Fig. 3C). Similar profiles of Muc2 promoter transactivation were observed with double mutants \#1, \#2, and \#4. Mutations of these Gata-4/Foxa binding sites led to total abroga-
A
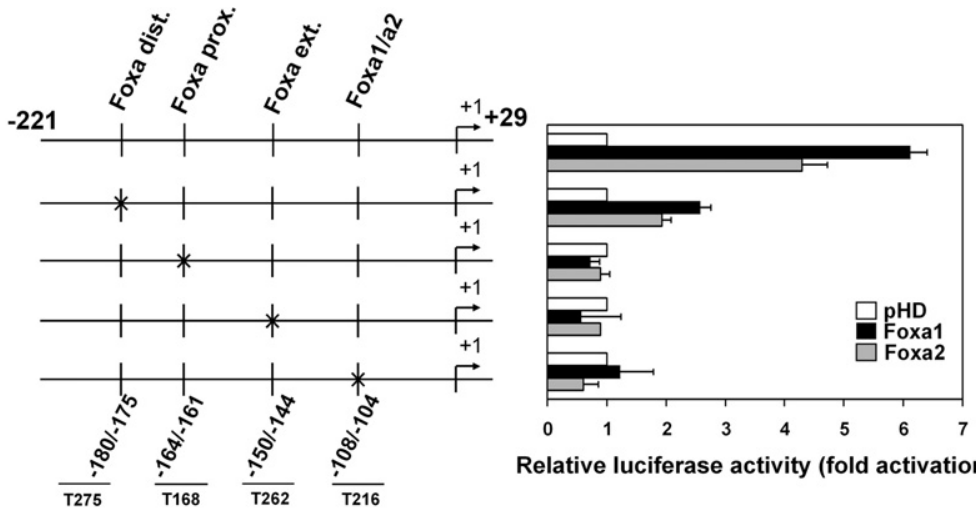

Relative luciferase activity (fold activation
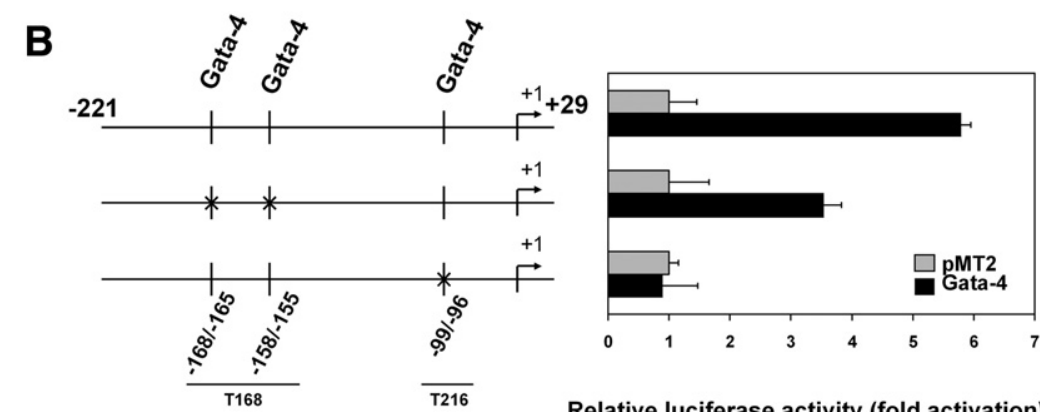

Relative luciferase activity (fold activation)
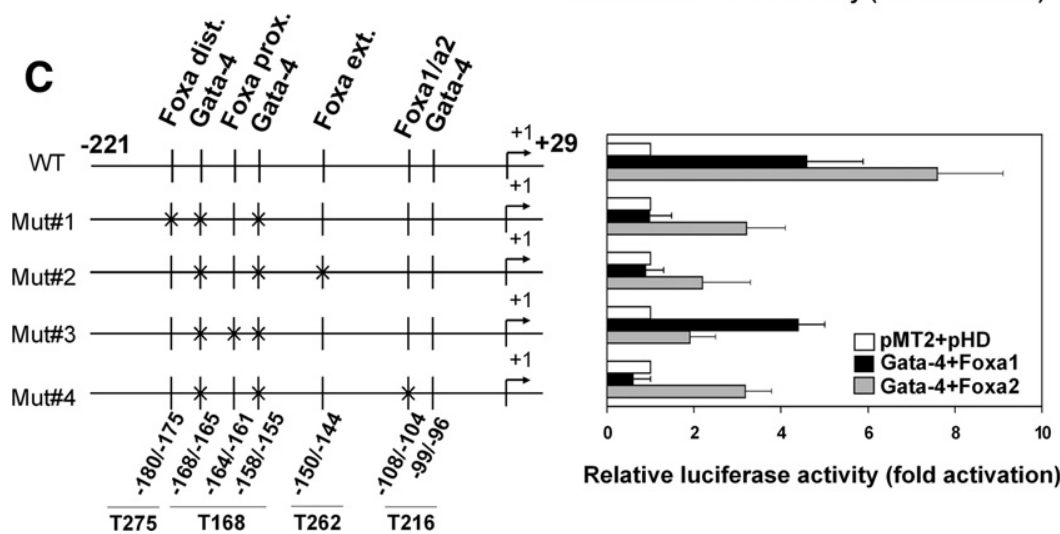

Relative luciferase activity (fold activation)

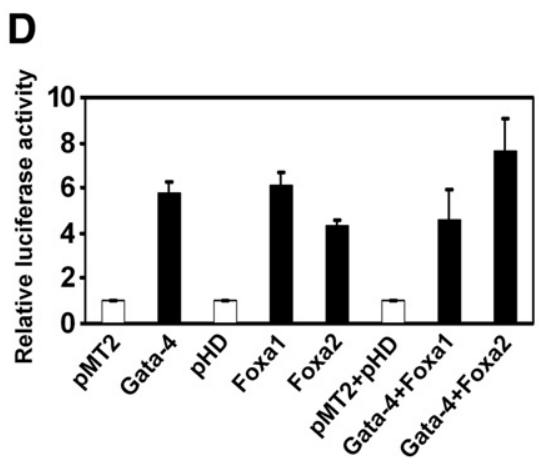

E

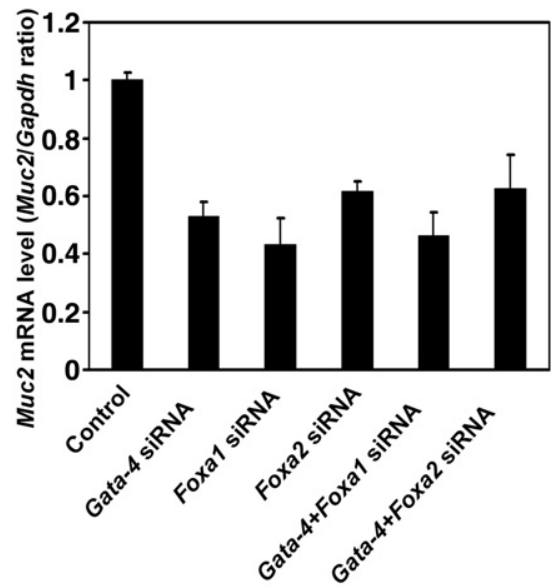

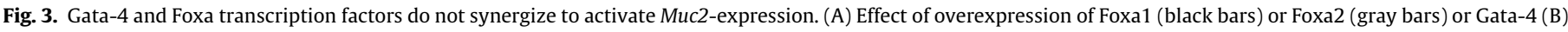

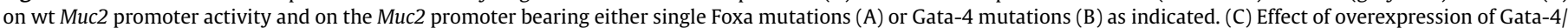

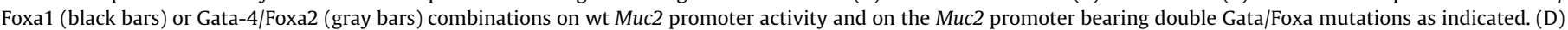

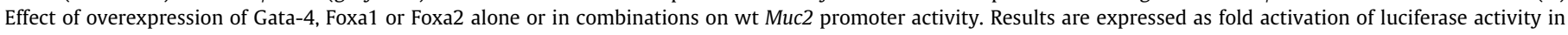

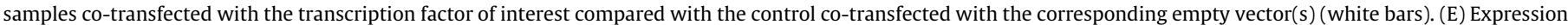

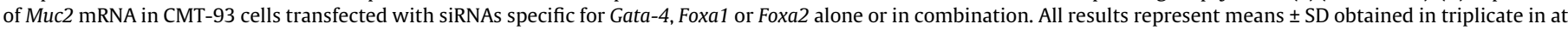
least three separate experiments. 
tion of the transactivation in the presence of Gata-4/Foxa1 (black bars) and partial inhibition (25\% remaining) in the presence of Gata-4/Foxa2. This indicates that in these mutants, Gata-4 mutation was preponderant in the presence of Foxa2 when compared to single mutations, whereas it was Foxa mutation that was responsible for the loss of the promoter activity in the presence of Foxa1. Mutant \#3 gave a different profile of Muc2 promoter activity. In that case, promoter activity was similar in the presence of Gata-4/Foxa1 (black bar), whereas $25 \%$ remained in the presence of Gata-4/Foxa2 (gray bar) when compared to wild-type (WT) constructs. Compared to single mutants this suggests that some promoter activity was restored in the presence of Foxa1 (black bar), whereas no additive effect was visualized for Gata-4/Foxa2 combination (gray bar). ied by co-transfection experiments (Fig. 3D) and by siRNA approach (Fig. 3E). Overexpression of Gata-4, Foxa1 or Foxa2 TFs resulted in an increased luciferase activity of the $-221 /+29$ Muc2 promoter construct (4- to 6-fold activation, Fig. 3D). No synergistic effect could be visualized when co-transfecting Gata- 4 in combination with either Foxa1 or Foxa2. The same absence of synergy was observed in siRNA experiments since double silencing of Gata-4 with Foxa1 or Foxa2 did not lead to increased repression of Muc2 mRNA expression (40-60\% decrease) when compared with single siRNAs (Fig. 3E). Altogether, these studies demonstrate that Gata4 and Foxa1/Foxa2 do not synergize to induce either Muc2 promoter activity or Muc2 mRNA expression.

Our study shows that Foxa1 and Foxa2 each have the individual capacity of activating Muc2-expression. Foxa1 has been described as a poor activator of gene transcription compared to Foxa2, and competition has been suggested as they can bind with the same DNA binding sequence [24]. In our studies both Foxa1 and Foxa2 were shown to equally bind the Muc2 promoter, but functional studies at the protein, RNA and promoter levels indicated that Foxa1 was slightly more efficient as a Muc2 activator. Gata, HNF, Foxa, and Cdx TFs are known to be able to act in synergy to regulate intestinal cell-specific genes [15-18]. Recruitment of specific combinations of these TFs at the promoter level will then occur and evolve as intestinal cells migrate to the villi and differentiate. In this report we could not show synergistic effect between Gata-4 and Foxa TFs. Foxa binding has been proposed to decompact chromatin and facilitate binding of other TFs, and thereby promote gene activation [12]. However, this does not seem to be the case for Muc2 in regard to Gata-4. The absence of synergy despite the close localization of the Gata-4 and Foxa1/Foxa2 cis-elements within the Muc2 promoter therefore indicates that these TFs will most likely act as competitors to regulate Muc2 transcription. Consequently, this also suggests that the amount of each transcription factor in the cell will be critical and will determine which will be controlling Muc2 transcription.

In summary, we identified Foxa1 and Foxa2 as important regulators of Muc2 gene expression, and showed that Foxa1 and Foxa2 (i) are both expressed in Muc2-expressing goblet cells in the mouse small intestine, (ii) are both potent activators of Muc2 promoter activity, (iii) mediate Muc2 regulation by directly interacting with their cognate elements within the Muc2 proximal promoter, and (iv) are both required for endogenous expression of Muc2. Our results identify Muc2, a goblet cell marker, as a new target gene of Foxa 1 and Foxa 2 and point out an important role for these transcription factors in Muc2 mucin expression in the intestine during goblet cell differentiation.

\section{Acknowledgments}

We thank C. Chauvin, M.-P. Ducourouble and M.H.M. Melis for their technical help. We thank Dr. J.K. Divine (Washington Univer-
Cooperation between Gata- 4 and Foxa1 or Foxa2 was then stud- sity, St. Louis, MO, USA) for the kind gift of pHD-Foxa1 and pHDFoxa2 expression vectors and Dr. S. Cereghini for the kind gift of pMT2-Gata-4 vector (UMR7622 CNRS, Université Pierre et Marie Curie, Paris, France).

This work was supported by grants from the Sophia Foundation for Medical Research (MVDS), INSERM/ZonMw-NWO (IVS, IBR) and $\mathrm{l}^{\prime}$ Association Francois Aupetit (IVS). A. Vincent is the recipient of a Conseil Régional Nord-Pas de Calais and the Institut National de la Santé et de la Recherche Médicale PhD fellowship.

Supplementary data associated with this article can be found, in the online version, at doi:10.1016/j.bbrc.2008.02.158.

\section{References}

[1] A.P. Corfield, D. Carroll, N. Myerscough, C.S. Probert, Mucins in the gastrointestinal tract in health and disease, Front. Biosci. 6 (2001) D1321D1357.

[2] I. Van Seuningen, P. Pigny, M. Perrais, N. Porchet, J.P. Aubert, Transcriptional regulation of the $11 \mathrm{p} 15$ mucin genes. Towards new biological tools in human therapy, in inflammatory diseases and cancer? Front. Biosci. 6 (2001) D1216D1234.

[3] M. van der Sluis, B.A.E. de Koning, A.C.J.M. de Bruijn, A. Velcich, J.P.P. Meijerink, J.B. van Goudoever, H.A. Büller, J. Dekker, I. van Seuningen, I.B. Renes, A.W.C. Einerhand, Muc2-deficient mice spontaneously develop colitis, indicating that MUC2 is critical for colonic protection, Gastroenterology 131 (2006) 117-129.

[4] M.P. Buisine, L. Devisme, T.C. Savidge, C. Gespach, B. Gosselin, N. Porchet, J.P. Aubert, Mucin gene expression in human embryonic and fetal intestine, Gut 43 (1998) 519-524.

[5] D.G. Silberg, G.P. Swain, E.R. Suh, P.G. Traber, Cdx1 and cdx2 expression during intestinal development, Gastroenterology 119 (2000) 961-971.

[6] P.G. Traber, D.G. Silberg, Intestine-specific gene transcription, Annu. Rev. Physiol. 58 (1996) 275-297.

[7] K. Zaret, Developmental competence of the gut endoderm: genetic potentiation by GATA and HNF3/fork head proteins, Dev. Biol. 209 (1999) 1-10.

[8] P. Mesquita, N. Jonckheere, R. Almeida, M.P. Ducourouble, J. Serpa, E. Silva, P. Pigny, F.S. Silva, C. Reis, D. Silberg, I. Van Seuningen, L. David, Human MUC2 mucin gene is transcriptionally regulated by $\mathrm{Cdx}$ homeodomain proteins in gastrointestinal carcinoma cell lines, J. Biol. Chem. 278 (2003) 51549-51556.

[9] M. van der Sluis, M.H. Melis, N. Jonckheere, M.P. Ducourouble, H.A. Buller, I. Renes, A.W. Einerhand, I. Van Seuningen, The murine Muc2 mucin gene is transcriptionally regulated by the zinc-finger GATA-4 transcription factor in intestinal cells, Biochem. Biophys. Res. Commun. 325 (2004) 952-960.

[10] H. Sasaki, B.L. Hogan, Differential expression of multiple fork head related genes during gastrulation and axial pattern formation in the mouse embryo, Development 118 (1993) 47-59.

[11] S.L. Ang, A. Wierda, D. Wong, K.A. Stevens, S. Cascio, J. Rossant, K.S. Zaret, The formation and maintenance of the definitive endoderm lineage in the mouse: involvement of HNF3/forkhead proteins, Development 119 (1993) 1301-1315.

[12] K.H. Kaestner, W. Knochel, D.E. Martinez, Unified nomenclature for the winged helix/forkhead transcription factors, Genes Dev. 14 (2000) 142-146.

[13] H. Ye, T.F. Kelly, U. Samadani, L. Lim, S. Rubio, D.G. Overdier, K.A. Roebuck, R.H. Costa, Hepatocyte nuclear factor $3 /$ fork head homolog 11 is expressed in proliferating epithelial and mesenchymal cells of embryonic and adult tissues, Mol. Cell. Biol. 17 (1997) 1626-1641.

[14] R. Hromas, R. Costa, The hepatocyte nuclear factor-3/forkhead transcription regulatory family in development, inflammation, and neoplasia, Crit. Rev. Oncol. Hematol. 20 (1995) 129-140.

[15] F. Boudreau, E.H. Rings, H.M. van Wering, R.K. Kim, G.P. Swain, S.D. Krasinski, J. Moffett, R.J. Grand, E.R. Suh, P.G. Traber, Hepatocyte nuclear factor-1 alpha, GATA-4, and caudal related homeodomain protein Cdx2 interact functionally to modulate intestinal gene transcription. Implication for the developmental regulation of the sucrase-isomaltase gene, J. Biol. Chem. 277 (2002) 3190931917.

[16] N. Jonckheere, A. Vincent, M. Perrais, M.P. Ducourouble, A.K. Male, J.P. Aubert, P. Pigny, K.L. Carraway, J.N. Freund, I.B. Renes, I. Van Seuningen, The human mucin MUC4 is transcriptionally regulated by caudal-related homeobox, hepatocyte nuclear factors, forkhead box A, and GATA endodermal transcription factors in epithelial cancer cells, J. Biol. Chem. 282 (2007) 22638-22650.

[17] S.D. Krasinski, H.M. Van Wering, M.R. Tannemaat, R.J. Grand, Differential activation of intestinal gene promoters: functional interactions between GATA-5 and HNF-1 alpha, Am. J. Physiol. Gastrointest. Liver Physiol. 281 (2001) G69-G84.

[18] H.M. Van Wering, T. Bosse, A. Musters, E. De Jong, N. De Jong, C.E. Hogen Esch, F. Boudreau, G.P. Swain, L.N. Dowling, R.K. Montgomery, R.J. Grand, S.D. Krasinski, Complex regulation of the lactase-phlorizin hydrolase promoter by GATA-4, Am. J. Physiol. Gastrointest. Liver Physiol. 287 (2004) G899-G909.

\section{Appendix A. Supplementary data}


[19] I. Van Seuningen, J. Ostrowski, X.R. Bustelo, P.R. Sleath, K. Bomsztyk, The K protein domain that recruits the interleukin 1-responsive $\mathrm{K}$ protein kinase lies adjacent to a cluster of c-Src and Vav SH3-binding sites. Implications that K protein acts as a docking platform, J. Biol. Chem. 270 (1995) 2697626985.

[20] G. Piessen, N. Jonckheere, A. Vincent, B. Hemon, M.P. Ducourouble, M.C. Copin, C. Mariette, I. Van Seuningen, Regulation of the human mucin MUC4 by taurodeoxycholic and taurochenodeoxycholic bile acids in oesophageal cancer cells is mediated by hepatocyte nuclear factor 1alpha, Biochem. J. 402 (2007) 81-91.
[21] V. Besnard, S.E. Wert, W.M. Hull, J.A. Whitsett, Immunohistochemical localization of Foxa1 and Foxa2 in mouse embryos and adult tissues, Gene Expr. Patterns 5 (2004) 193-208.

[22] S.S. Myatt, E.W. Lam, The emerging roles of forkhead box (Fox) proteins in cancer, Nat. Rev. Cancer 7 (2007) 847-859.

[23] H. Nakshatri, S. Badve, FOXA1 as a therapeutic target for breast cancer, Expert Opin. Ther. Targets 11 (2007) 507-514.

[24] S.A. Duncan, M.A. Navas, D. Dufort, J. Rossant, M. Stoffel, Regulation of a transcription factor network required for differentiation and metabolism, Science 281 (1998) 692-695. 